\title{
Utilizing Activated Carbon Developed from Banana Peels as Permeable Reactive Barrier in Copper Removal from Polluted Groundwater
}

\author{
Shahzanan Abbas Al Haider ${ }^{1 *}$, Suad Al Fatlawi², Mohsin J. Nasir ${ }^{3}$ \\ 1 Chemical Engineering and Petroleum Industries Department, Al-Mustaqbal University College, Babylon, Iraq \\ 2 Department of Environmental Engineering at Faculty of Engineering, University of Babylon, Iraq \\ 3 Al-Mussaib Technical Institute, Al-Furat Al-Awsat Technical University, 51009 Babylon, Iraq \\ * Corresponding author's e-mail: shah.zanaan.abbas@mustaqbal-college.edu.iq
}

\begin{abstract}
The opportunity of utilizing activated carbon prepared from banana peels (BPAC) as a permeable reactive barrier (PRB) to eliminate copper $\left(\mathrm{Cu}^{+2}\right)$ from the contaminated ground water has been explored. The activated carbon was prepared from banana peels by chemical activation utilizing a drenching agent, for example, a phosphoric acid $\left(\mathrm{H}_{3} \mathrm{PO}_{4}\right)$. The Influence of different factors including initial copper amount, contacting duration, agitation speed, initial $\mathrm{pH}$ of the solution and sorbent dosage was studied in batch experiments. The optimum magnitudes for these factors that resulted in the highest copper removing efficacy $(96 \%)$ were 40 minutes, 6, $250 \mathrm{rpm}, 50 \mathrm{mg} / \mathrm{l}$, and $1 \mathrm{mg} / 100 \mathrm{ml}$, respectively. The isotherm models of Freundlich and Langmuir have been utilized to analyze the sorption data for $\mathrm{Cu}^{+2}$ ions acquired via batch studies. The Langmuir model has been utilized to explain the sorption of $\mathrm{Cu}^{+2}$ onto BPAC, according to the findings. The partial differential formulas that describe copper transport in one-dimensional (1D) under equilibrium conditions have been solved utilizing COMSOL Multiphysics 3.5a software based on the finite element technique. The PRB has a significant function in preventing the copper plume from moving, according to the expected findings (COMSOL solution) and experimental findings. Finally, the excellent agreement between anticipated (theoretical) and actual findings, with an RMSE of less comparison with $0.1 \%$, demonstrated that these techniques are useful and efficient instruments for describing copper transport processes.
\end{abstract}

Keywords: Copper, banana peels, ground water, activated carbon, the permeable reactive barrier, migration

\section{INTRODUCTION}

Groundwater pollution by organic and inorganic chemicals was a topic of discussion because since Industrial Revolution (Abd Ali et al., 2019). Groundwater, which is water that seeps down from the surface of the earth by migrating thru the matrix of soil and gaps in geologic formations, is usually more dependable for usage comparison with surface water (Faisal \& Abd Ali, 2014). Historically, the pump-and-treating technique was the most widely utilized technique for groundwater remediation. This technique is often expensive, laborious, and unsuccessful at removing sufficient pollutants to restore groundwater to acceptable potable water standards in a reasonable amount of duration. The pump failure and treating was mostly due to the inability to remove pollutants from the subsurface owing to hydrogeologic conditions and trapped residual contaminated material. As a result, (PRB) technology was utilized to treating groundwater polluted with various kinds of pollutants. It has been shown to be more cost-effective comparison with pump and treating, and it has the ability to reduce contamination spread (Di Natale, 2008). Activated carbon has a broad range of uses and has been shown to be an efficient adsorbent for removing widely inorganic and organic pollutants from a variety of media. Because a result, numerous researchers 
are pursuing the creation of low-cost activated carbon, as commercial activated carbon remains prohibitively costly (Abd Ali, 2016).

Thus, the importance of the present study is the preparation of activated carbon from banana peels (BPAC) as an inexpensive and efficient reactive material and the ability of utilizing of this substance in PRB for the elimination of $\mathrm{Cu}^{+2}$ from polluted ground water.

\section{METHODOLOGY}

\section{Material}

Banana peels were cut into small pieces, dried utilizing an electrical oven at temperature $105^{\circ} \mathrm{C}$ for two hours, and crushed. Banana peels have been washed by hot water and dried utilizing an electrical furnace at temperature $105{ }^{\circ} \mathrm{C}$. After drying were grinded into a fine powder by utilizing a domestic blender, and after that sieved into molecule size from $75 \mu \mathrm{m}$ to $600 \mu \mathrm{m}$ to get the smallest molecules as shown in Figure 1.

The production of activated carbon from banana peels involves two stages: drenching and a combined step of carbonization and activation of peels. In the initial stage, the dried banana peels were placed in glass containers. The two solutions usually utilized in the chemical treatment process of producing activated carbon are Zinc Chloride and Phosphoric Acid. Phosphoric acid was chosen over zinc chloride because it is relatively safer comparison with zinc chloride (Yagsi, 2012). During this step, a phosphoric acid (3M) was poured carefully into the containers containing banana peels by a drenching proportion of ( $2 \mathrm{~g}$ of peels drenched in $4 \mathrm{ml}$ of $3 \mathrm{M}$ of phosphoric acid) at temperature $25^{\circ} \mathrm{C}$ and a drenching duration of 24 hours. At the end of the drenching duration, the drenched peels were left in the air for partial dryness and at that duration dried utilizing an oven at temperature $120^{\circ} \mathrm{C}$ for two hour.

In the second step, the peels were placed on a metallic plate and subjected to temperature of $500{ }^{\circ} \mathrm{C}$ for one hour (Rouabeh \& Amrani, 2012). This heating period was chosen depending on the previous trials of various heating duration. The peels have been fully carbonized to ash when the heating duration was increased to more over two hours, according to the findings of numerous experimental experiments. After one hour of carbonization duration, the product was taken to a flask and distilled hot water was added. Then, the peels were washed by hot water until the $\mathrm{pH}=7$ was achieved, and the product was dried utilizing an electric oven at temperature $120^{\circ} \mathrm{C}$ as to remove any undesired moisture within the particles And then., the peels were grinded and sieved thru $75-600 \mu \mathrm{m}$ to get powdered activated carbon of banana peels to be utilized in present experiments of ground water treatment in the present study. Samples of banana peels are shown in the Figure 1. The sandy soil was utilized as an aquifer. The sandy soil has a molecule size appropriation gone thru $75 \mu \mathrm{m}-1 \mathrm{~mm}$.

The salt of $\mathrm{Cu}\left(\mathrm{NO}_{3}\right)_{2}$ (made by $\mathrm{BDH}, \mathrm{UK}$ ) has been set and supplementary to the water to acquire required amount.

\section{Batch experiments}

The batch tested was conducted at fixing certain experimental factors while differing other factors such that:

- The temperature was set to $25^{\circ} \mathrm{C}$ to perform sorption isotherms

- Interaction duration $20,40,60,80,100$ and 120 min was set.

- $\mathrm{pH}$ magnitudes of 2, 4, 6, and 8 were explored.

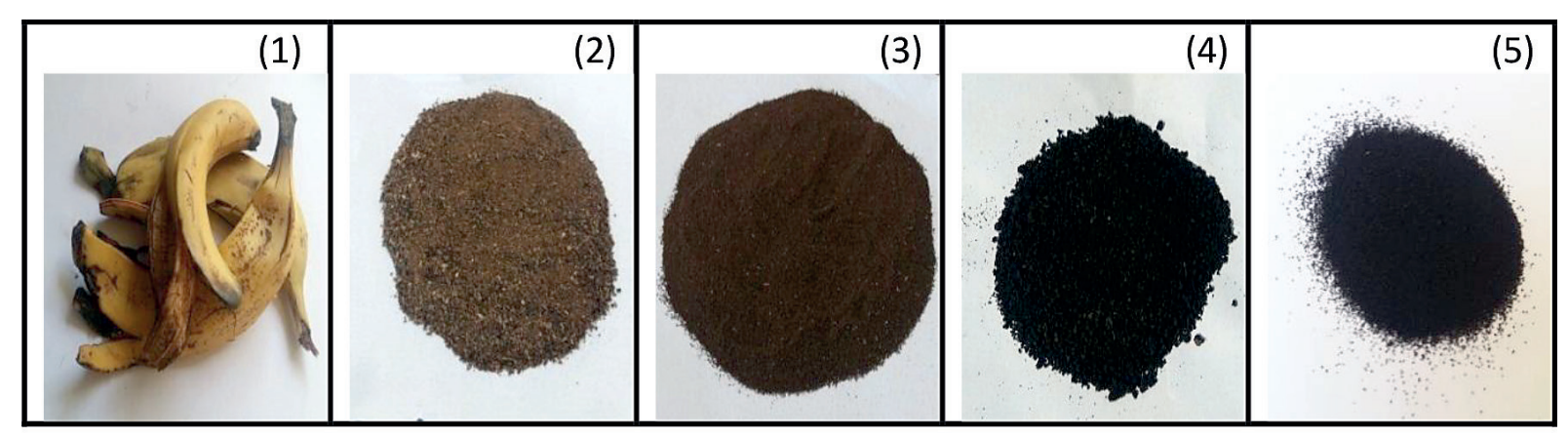

Figure 1. Before cutting and drying, (2) after drying, (3) powdered in organic state, (4) after soaking, (5) powdered activated carbon of banana peels. 
- Sorbent dosages of $0.1,0.25,0.50,1,2,3,4$ and $5 \mathrm{~g}$ activated carbon/100 $\mathrm{ml}$ were tested.

- The amount of copper 250, 200, 150, 100 and $50 \mathrm{mg} / \mathrm{l}$ were explored.

- Agitation speeds of $50,100,150,200$, and $250 \mathrm{rpm}$ were inspected.

A series of five $250 \mathrm{ml}$ flasks have been utilized to contain $100 \mathrm{ml}$ of $1 \mathrm{~g}$ activated carbon at which every copper amount is placed in every flask, the flasks were firmly put inside a shaker incubator and agitated for changed periods of duration. Permanent volume $(20 \mathrm{ml})$ of solution was pipette out and filtered (Filter paper kind Teknik No. 1) to gauge the residual amounts of copper left in aqueous solution. A sample of $10 \mathrm{ml}$ of filtrate was withdrawn and estimated for the dissolved copper amount utilizing atomic absorption spectrophotometer (AAS). Formula 1 has been utilized to determine the quantity of copper retained in the activated carbon phase $\left(q_{e}\right)$ based on the optimum experimental findings (Chen et al., 2015):

$$
q_{e}=C_{o}-C_{e} \cdot V \cdot m
$$

where: $C_{o}-$ is initial contaminant amount in solution $(\mathrm{mg} / \mathrm{L})$,

$C_{e}-$ is balance contaminant amount in solution $(\mathrm{mg} / \mathrm{L})$,

$V$ - the solution's size in the flask (L),

$m$ - the adsorbent's mass of activated carbon $(\mathrm{g})$.

The Langmiur and Freundlich models have been formed by graphing the qe in contradiction of of the $C_{e}$ at consistent temp. Langmuir formula (2) and Freundlich formula (3) models have been uses for the sorption data explanation (Wang et al. 2009) as follows:

$$
\begin{gathered}
q_{e}=a \cdot b \cdot C_{e 1}+b \cdot C_{e} \\
q_{e}=K_{F} \cdot C_{e 1} \cdot n
\end{gathered}
$$

where: $a$ - is the capability of maximum adsorption $(\mathrm{mg} / \mathrm{g})$,

$b-$ the constant $(1 / \mathrm{mg})$,

$K_{F}$ - the coefficient of Freundlich sorption $(\mathrm{mg} / \mathrm{g})$,

$n$ - coefficient of empirical.

\section{Batch experiments}

The adsorber configuration used in this research is demonstrated in Figure 2 as a schematic diagram. This adsorber is made of a Perspex column with a height and diameter of 80 and $5 \mathrm{~cm}$, respectively; the column has seven testing ports spaced $70 \mathrm{~cm}$ (port 7), 60 (port 6), 48 (port 5), 42 (port 4), 36 (port 3), 24 (port 2), and 12 (port 1) from the highest. Stainless steel fittings with Viton stoppers must be utilized to build these ports. Sample has been done at predetermined intervals from sampling ports with a syringe placed into the column's center axis.

The column was packed with soil specimen with depth of $36 \mathrm{~cm}$ measured from the bottom of column. At that point, activated carbon with depth of $6 \mathrm{~cm}$ measured from the top surface of soil. Once more, the soil of depth $18 \mathrm{~cm}$ was

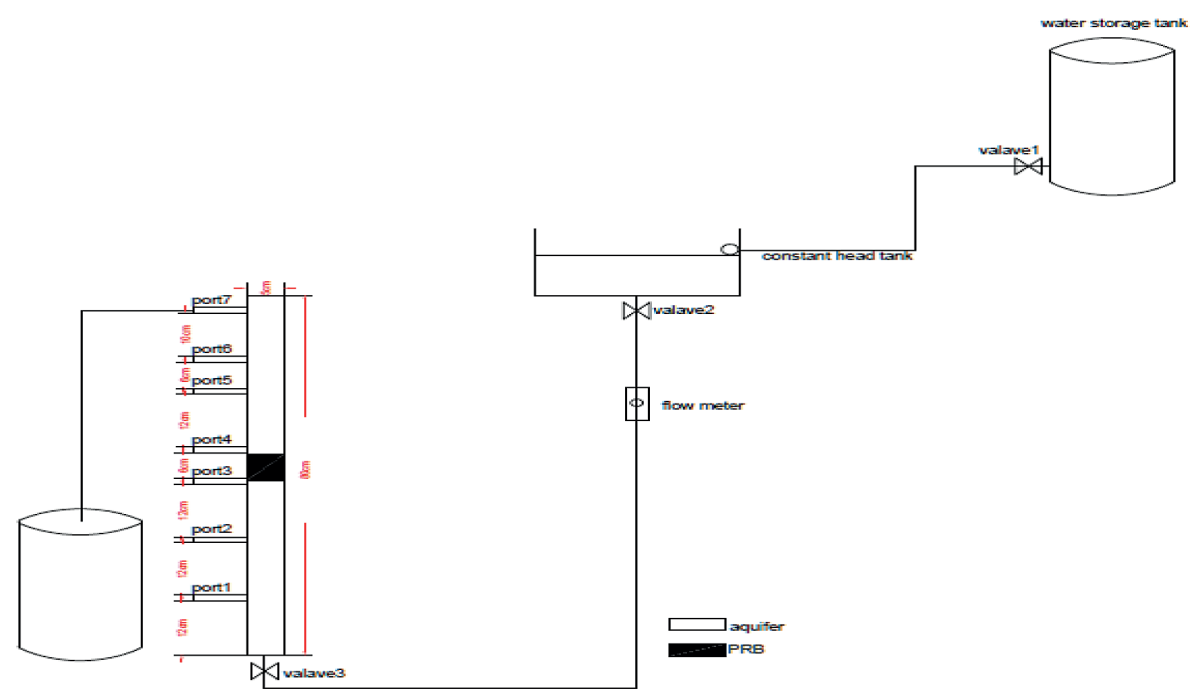

Figure 2. Graphical diagram of the laboratory-column scale. 
measured from the top of activated carbon. The copper solution was introduce into the column from controlled storage reservoir by unchangeable head flow, three valves and flow-meter. Two rate of flow magnitudes (5 and 10) $\mathrm{ml} / \mathrm{min}$ have been chosen for the column test. Monitoring the amount of copper along the column length in the effluent from testing ports has been conduct for a duration of 25 hours, then amount of water have been took regularly after $5,10,15,20$ and 25 hours from these ports and directly presented in glass vitals and then subject to analyzing by atomic adsorption spectrophotometer.

\section{RESULTS AND DISCUSSION}

\section{The influence of interaction duration and $\mathrm{pH}$ magnitude}

Figure 3 demonstrates the impact of interaction duration and $\mathrm{pH}$ magnitude on elimination efficacy of copper utilizing $1 \mathrm{~g}$ of BPAC inserted to $100 \mathrm{ml}$ of copper solution at $25^{\circ} \mathrm{C}$. This figure show, at beginning, raising rate of adsorption as fast as interaction duration raised till reaching the equilibrium duration (40 $\mathrm{min}$ ). This may be because of the availability of a big quantity of copper attaches to the sorbent. Since the development of replusive interactions between the metals on solid surfaces and in the liquid phase, the sorption rate decreased as the number of empty surfaces decreased [El-Sayed et al. 2010]. As well as the reduction in the competition between $\mathrm{Cu}^{+2}$ and proton for surface sites causes the raise in the removing of copper on increasing $\mathrm{pH}$, this finding a

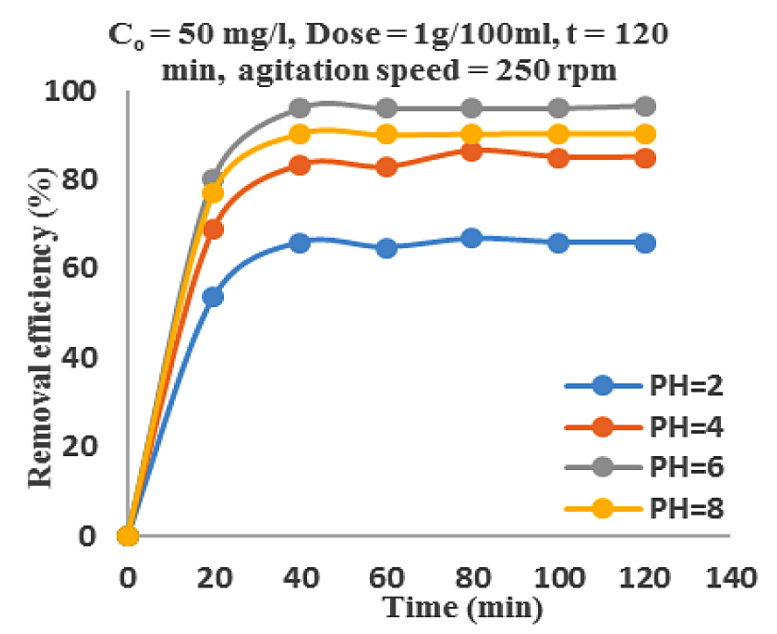

Figure 3. Elimination efficacy of $\mathrm{Cu}^{+2}$ by BPAC as a role of interaction duration and $\mathrm{pH}$. reduce in the columbic repulsion of sorbing copper. It is obvious from figure below that the higher elimination efficacy of $\mathrm{Cu}^{+2}$ was accomplished at $\mathrm{pH}$ of 6 .

\section{The influence of activated carbon dosage}

The elimination efficacy of copper on adsorbent (activated carbon) dosage was calculated by changing the quantity of activated carbon from 0.1 to $5 \mathrm{~g}$ inserted to $100 \mathrm{~mL}$ of solution as appeared in Figure 4. This figure demonstrated that the raising of the activated carbon dosage from 0.1 to $1 \mathrm{~g}$ at initial copper amount $(50 \mathrm{mg} / \mathrm{l})$. This was relied upon because of the way that the higher portion of the activated carbon amount in the solution, the larger obtainability of active sites. This implies that the more activated carbon particles there are, the more iron surface-active places there are for metal molecules to collide with, resulting in a faster metal removal effectiveness (Rahmani et al. 2010).

\section{The influence of initial copper amount}

Figure 5 presents the influence of initial amount of copper on its removing efficacy. Its shows that once increasing the original amount of copper from 50 to $250 \mathrm{mg} / \mathrm{L}$, the removing efficacy reduces from $96 \%$ to $38.29 \%$, this characterizes the obtainable saturation active sites on the activated carbon to interact with pollutant, so with increasing amount the less positive places became included in the process (Jain et al. 2015).

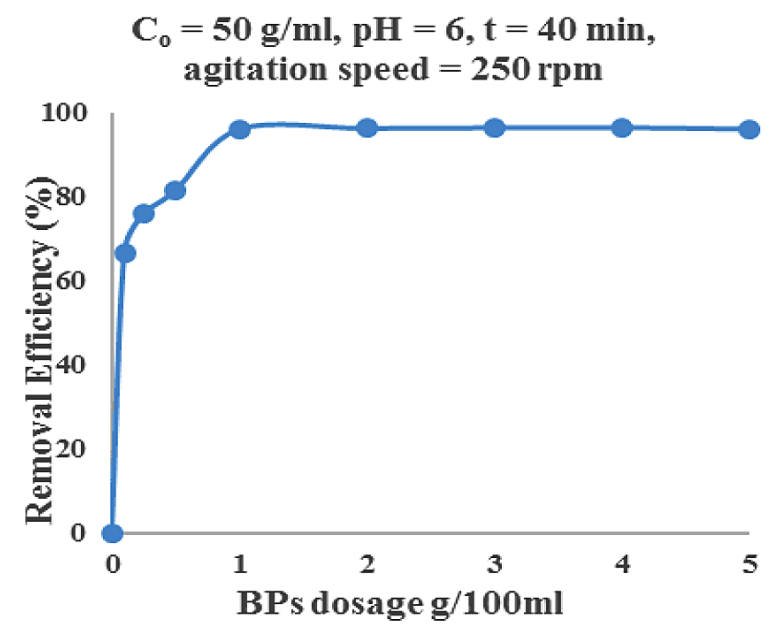

Figure 4. The influence of (a) DPSAC, (b) PSAC and ASAC dosages on elimination efficiencies of copper 


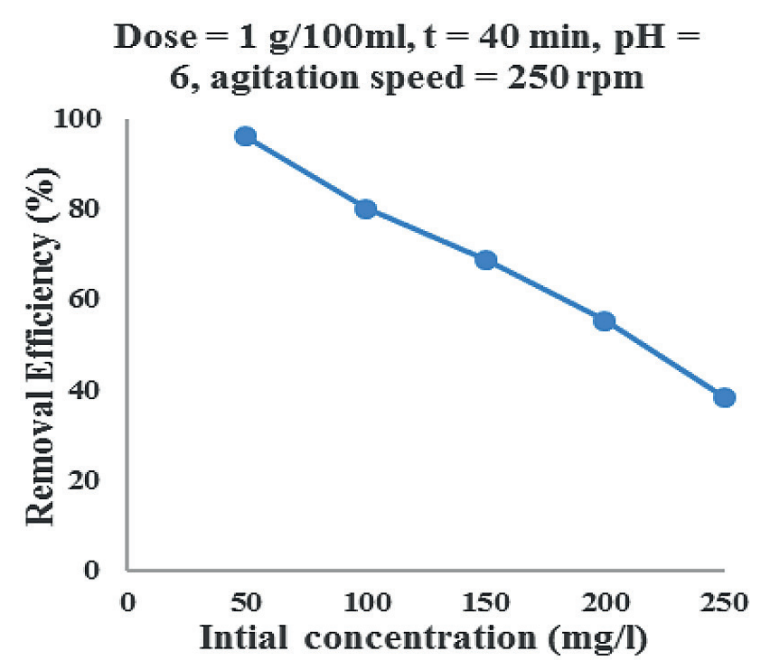

Figure 5. The influence of copper amount on elimination efficacy of copper for BPAC as adsorbents

\section{The influence of agitation speed}

Figure 6 demonstrations that the elimination efficacy of $\mathrm{Cu}^{+2}$ before shaker was $64.382 \%$ and the elimination efficacy of copper raises thru the raise rate of shaking. There was a gradual raised in elimination efficacy of copper when agitation velocity was raised from zero to $250 \mathrm{rpm}$ that approximately $96 \%$ of the copper is removed for BPAC. This could be due to enhancing the copper's diffusion towards the reactive medium surface (activated carbon) and more contacting between the binding sites and the copper in the solution.

\section{Sorption isotherm}

Table 1 present the findings of the investigational runs concerned the $D_{L}$ measurement at changed amount of speed $(V)$ for soil aquifer and activated carbon were taken a linear relationships as pursues:

$$
\begin{gathered}
D_{L}=35.046 V+0.0262 \\
\text { for soil } R^{2}=0.9998
\end{gathered}
$$

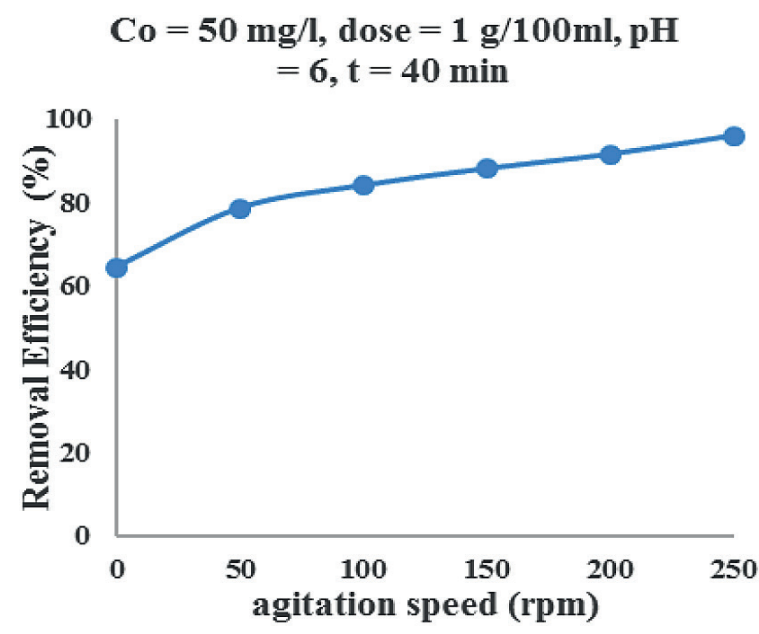

Figure 6. Influence of agitation speed on elimination efficacy of copper for BPAC as adsorbents

$$
D_{L}=15.267 U+0.029
$$

These equations are occupied the overall kind of DL as pursues:

$$
D_{L}=D_{\text {mesh }}+\tau \cdot D_{o}
$$

where: $D_{\text {mesh }}$ and $D_{o}$ - are the coefficients of mechanical dispersion and effective molecular diffusion.

\section{MODELING APPLICATION}

Advection dispersion processes is the cause of copper migrate in a porous medium, so that the one-dimensional system of copper migration in the porous media can be represented by Formula (7) (Jain et al.2015).

$$
D_{z 2} \cdot C_{C u} \cdot z_{2}-V z \cdot \partial C_{C u} \cdot \partial z=\partial C_{C u} \cdot \partial t+b \cdot n \cdot q \cdot \partial t
$$

where: $C_{C u}$ - copper mass amount in water,

$V_{z}$ - speed of flow,

$D_{z}-$ coefficient of longitudinal dispersion in the direction $z$,

Table 1. Measured magnitudes of the longitudinal dispersion coefficient and dispersivity for utilized mediums as a function of pore speed

\begin{tabular}{|c|c|c|c|c|}
\hline Flow rate $(\mathrm{ml} / \mathrm{min})$ & 5 & & 10 & 15 \\
\hline \multirow{3}{*}{ PDPAC } & $\mathrm{V}(\mathrm{cm} / \mathrm{s})$ & 0.0125 & 0.0249 & 0.0374 \\
\cline { 2 - 5 } & $\mathrm{D}_{\mathrm{L}}\left(\mathrm{cm}^{2}\right)$ & 0.156 & 0.186 & 0.212 \\
\cline { 2 - 5 } & $\mathrm{aL}(\mathrm{cm})$ & & 2.2488 & \\
\hline
\end{tabular}


$\rho_{b}-$ bulk density of dry adsorbing material,

$q$-copper amount on solid.

The subsequent term on the right side of Formula (7) be able to change by the Langmuir model the Formula (2) under isothermal conditions. Factors and constants associated to the soil and activated carbon as reactive materials adopted here for verification of model have been assessed, either thru laboratory tests or thru approximation utilizing literature data (Table 2).

Figure 7 demonstrations the normalized amount lines of $\mathrm{Cu}^{+2}$ in the soil, determined by the COMSOL software, without and with the absence of PRB at flow rate magnitudes of $5 \mathrm{~mL} / \mathrm{min}$ after
$5,10,15,20$ and 25 hours. This figure demonstrates the potential role of the PRB in hindering the spread of the copper.

A comparison between the theoretical (COMSOL solution) and experimental findings for copper amounts thru the transport of the copper at 5, $10,15,20$ and 25 hours and flow rates of $5 \mathrm{ml} / \mathrm{min}$ along the sampling column as exposed in Figure 8. It has been observable from figure below that there is a nearly contract between experimental and expected findings. In addition, to discovery the grade of contract between these findings a statistical tool was utilized the root-mean squared error (RMSE) (Anderson et al. 2015, Krause et al. 2005). The RMSE less comparison with $0.1 \%$, confirming a nearly contract.

Table 2. Factors, constants, boundary and initial conditions utilized in the transport modeling of copper in pilot plant column

\begin{tabular}{|c|c|c|}
\hline Item & Location & Kind/ Magnitude \\
\hline \multirow{7}{*}{ Aquifer characteristics } & \multirow{4}{*}{ Sandy soil } & Porosity $(n A)=0.44$ \\
\hline & & $\begin{array}{l}\text { Sandy soil depth before PRB }(\mathrm{cm})=36 \\
\text { Sandy soil depth after PRB }(\mathrm{cm})=32\end{array}$ \\
\hline & & Longitudinal dispersivity (LD) $(\alpha \mathrm{L}, \mathrm{cm})=35.046$ \\
\hline & & Bulk density $(\mathrm{g} / \mathrm{cm} 3)=1.47415$ \\
\hline & \multirow{3}{*}{ BPAC } & Porosity $(n B)=0.42$ \\
\hline & & Barrier bed depth $(\mathrm{cm})=6.0$ \\
\hline & & $\operatorname{LD}(\alpha \mathrm{L}, \mathrm{cm})=2.2488$ \\
\hline \multirow{2}{*}{ Initial condition } & \multicolumn{2}{|c|}{ The initial amount of $\mathrm{Cu}^{+2}=0.0 \mathrm{mg} / \mathrm{l}$} \\
\hline & \multicolumn{2}{|c|}{ Amount of $\mathrm{Cu}^{+2}$ at distance $0.0 \mathrm{~cm}=50 \mathrm{mg} / \mathrm{l}$} \\
\hline Boundary conditions & \multicolumn{2}{|c|}{ Advection flux $(\partial \mathrm{C} / \partial \mathrm{z})$ at distance $60 \mathrm{~cm}=0.0$} \\
\hline
\end{tabular}
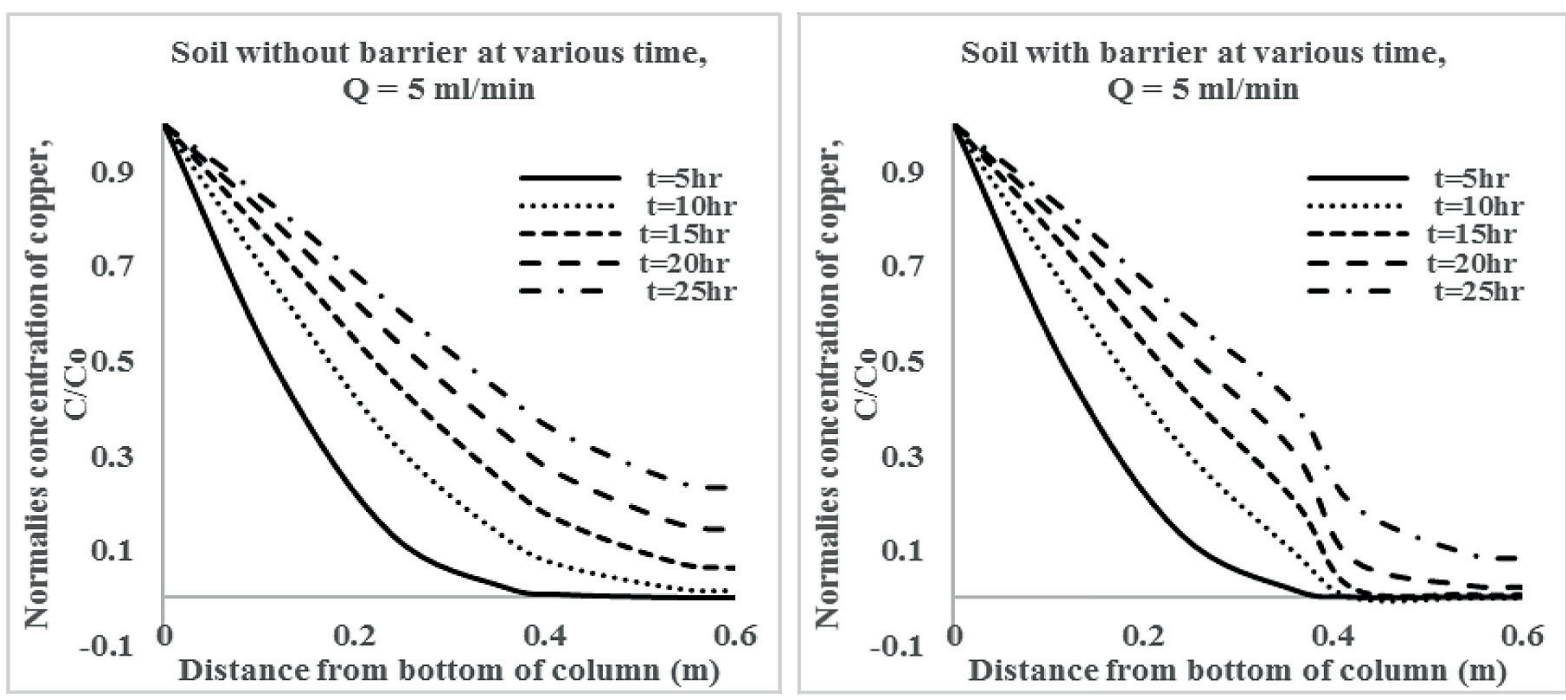

Figure 7. The normalized amount of copper barrier on BPAC by COMSOL software across the distance of the column with and without the attendance of PRB at 5, 10, 15, 20 and 25 hours 

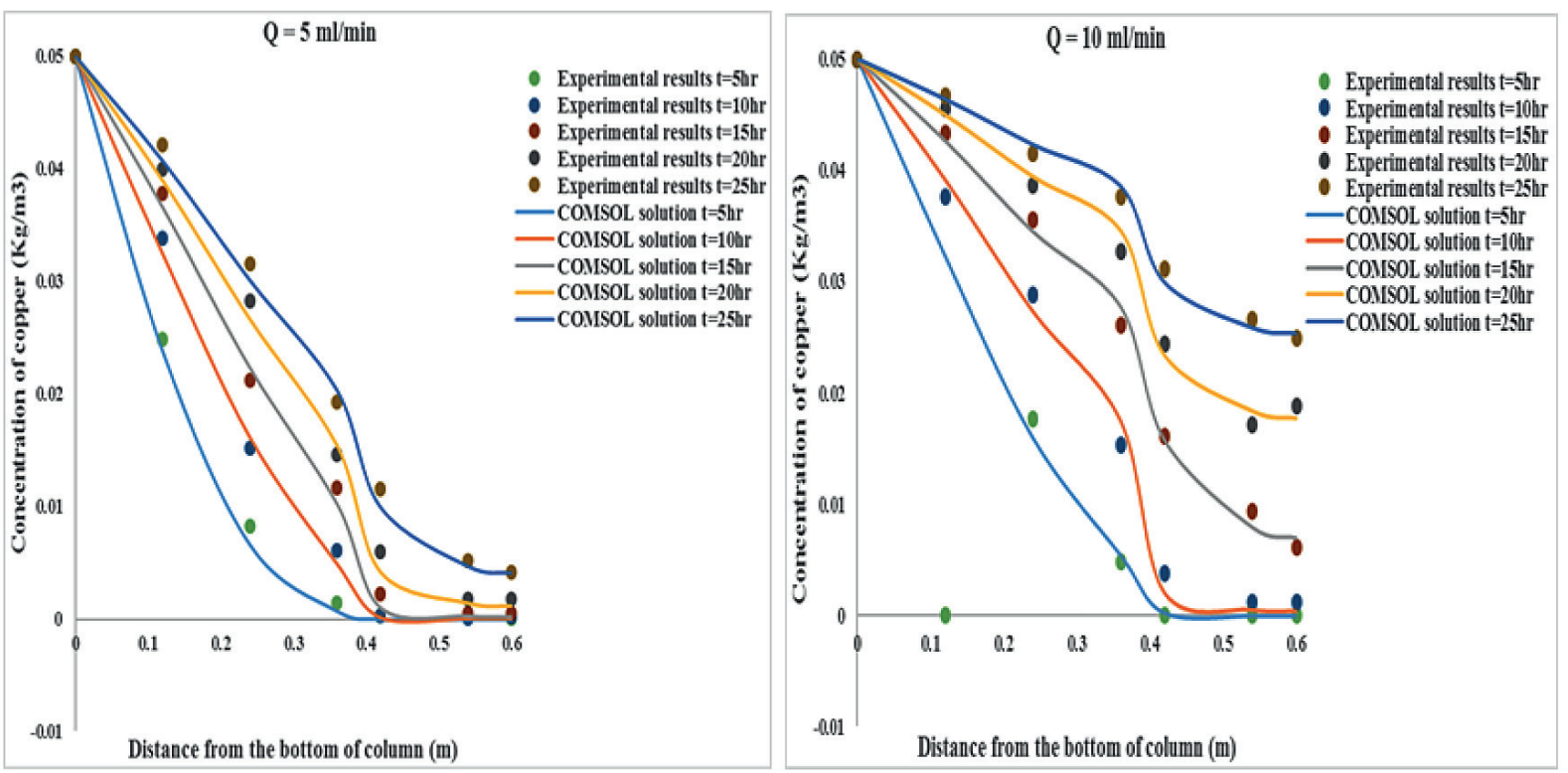

Figure 8. The differences between predicted (COMSOL solution) and experimental findings for copper amounts on BPAC at two flow rate magnitude.

\section{CONCLUSION}

The batch results demonstrated that the copper interaction with DPSAC significantly influenced balance interaction time, copper concentration, $\mathrm{pH}$ value, agitation velocity and dosage of activated carbon. The better estimation of these limits that will accomplish the greatest elimination efficiency of $\mathrm{Cu}^{+2}(95.542 \%)$ were $100 \mathrm{~min}$, $50 \mathrm{mg} / \mathrm{L}, 6,250 \mathrm{rpm}$ and $3 \mathrm{~g} / 100 \mathrm{~mL}$, respectively. Sorption data of copper on the DPSAC were corresponded well with the Langmuir and Freundlich sorption models. However, Langmuir model with the maximum $\mathrm{R}^{2}$ was selected in the copper migration through the APSAC. 1D numerical model, solved by COMSOL software under equilibrium condition, showed that the DPSAC is an effective technique to hinder the copper plume. However, a perfect contract between the predicted and experimental results with RMSE less than $0.1 \%$. Experimental results proved that the DPSAC were a good choice as an inexpensive and efficient reactive material for the PRB to eliminate the $\mathrm{Cu}^{+2}$ from contaminated groundwater.

\section{REFERENCES}

1. Abd Ali Z.T. 2016. Using activated carbon developed from iraqi date palm seeds as permeable reactive barrier for remediation of groundwater contaminated with copper. Al-Khwarizmi Engineering Journal, 12(2), 34-44.
2. Abd Ali Z.T., Flayehb H.M., Ibrahimc M.A. 2019. Numerical modeling of performance of olive seeds as permeable reactive barrier for containment of copper from contaminated groundwater. Desalination and Water Treatment, 139, 268-276.

3. Anderson M.P., Woessner W.W., Hunt R.J. 2015. Applied groundwater modeling: simulation of flow and advective transport. Academic Press.

4. Chen I.-P., Kan C.-C., Futalan C.M., Calagui M.J.C., Lin S.-S., Tsai W.C., Wan M.-W. 2015. Batch and fixed bed studies: Removal of copper (II) using chitosan-coated kaolinite beads from aqueous solution. Sustainable Environment Research, 25(2).

5. Di Natale F., Di Natale M., Greco R., Lancia A., Laudante C., Musmarra D. 2008. Groundwater protection from cadmium contamination by permeable reactive barriers. J. Hazard. Mater., 160(2-3), 428-434.

6. El-Sayed G., Dessouki H., Ibrahim S. 2010. Biosorption of $\mathrm{Ni}(\mathrm{II})$ and $\mathrm{Cd}(\mathrm{II})$ ions from aqueous solutions onto rice straw. Chemical Sciences Journal, \#A259381893.

7. Faisal A.A. and Abd Ali Z.T. 2014. Using granular dead anaerobic sludge as permeable reactive barrier for remediation of groundwater contaminated with phenol. Journal of Environmental Engineering, 141(4), 04014072.

8. Jain M., Garg V., Garg U., Kadirvelu K., Sillanpaa M. 2015. Cadmium removal from wastewater using carbonaceous adsorbents prepared from sunflower waste. International Journal of Environmental Research, 9(3), 1079-1088.

9. Rahmani A., Ghaffari H., Samadi M. 2010. Removal of arsenic (III) from contaminated water by 
synthetic nano size zerovalent iron. World Academy of Science, Engineering and Technology, 62, 1116-1119.

10. Reddi L. and Inyang H.I. 2000. Geoenvironmental engineering: principles and applications. CRC Press.

11. Yagsi N.U. 2004. Production and Characterization of Activated Carbon from Apricot Stones. Thesis. Middle East Technical University.

12. Krause P., Boyle D., Bäse F. 2005. Comparison of different efficiency criteria for hydrological model assessment. Advances in Geosciences, 5, 89-97.

13. Rouabeh I. and Amrani M. 2012. Equilibrium modeling for adsorption of $\mathrm{NO}_{3}$ from aqueous solution on activated carbon produced from pomegranate peel. Journal of Advances in Environmental Research, 1(2), 143-151.

14. Wang S., Nan Z., Li Y., Zhao Z. 2009. The chemical bonding of copper ions on kaolin from Suzhou, China. Desalination, 249(3), 991-995. 